\title{
Preliminary criteria for the energy sector: environmental and economic efficiency of investment projects
}

\author{
Anzhelika Karaeva ${ }^{1,2, *}$,Elena Magaril ${ }^{2}$, Vincenzo Torretta ${ }^{1}$, and Elena Cristina Rada ${ }^{1, *}$ \\ ${ }^{1}$ Insubria University, Department of Theoretical and Applied Sciences, via G.B. Vico 46, Varese, \\ Italy \\ ${ }^{2}$ Ural Federal University, Department of Environmental Economics, Mira-str. 19, Ekaterinburg, \\ Russian Federation
}

\begin{abstract}
Ecological and economic assessment is a key stage in the selection process of investment projects as it defines their efficiency and allows to forecast their likely impact on the environment and the socio-economic situation of the territory. Approaches to the efficiency assessment of investment projects include only basic criteria and do not sufficiently consider industryspecific. The energy sector is a significant primary sector in the global economy that directly affects the standard of living, energy resources availability for population and for the productive sector of economy and has a considerable impact on the environment. Therefore, the efficiency assessment process of investment project in the energy industry should comprise criteria which will respond to the branch specificity and provide accurate data about potential environmental and socio-economic consequences of project's implementation in both the short and the long-term run. The paper aims to propose a list of environmental criteria for improving the process of the ecological and economic efficiency assessment of energy investment projects, considering also the Circular Economy concepts. The list is based on the results of the expert survey carried out by the authors and might be used for multiple-criteria decision analysis of the investment projects.
\end{abstract}

\section{Introduction}

Nowadays the energy sector is undergoing a number of structural changes that correspond to the context of the 4th industrial revolution and the goals of sustainable development and Circular Economy concepts [1-3]. According to the last statistical data, the energy sector produced $48.7 \%$ of all $\mathrm{CO}_{2}$ emissions into the atmosphere in 2018 , while in 2000 its share was $47.0 \%$ (fig. 1) [4].

\footnotetext{
*Corresponding authors: akaraeva@uninsubria.it, elena.rada@uninsubria.it
} 


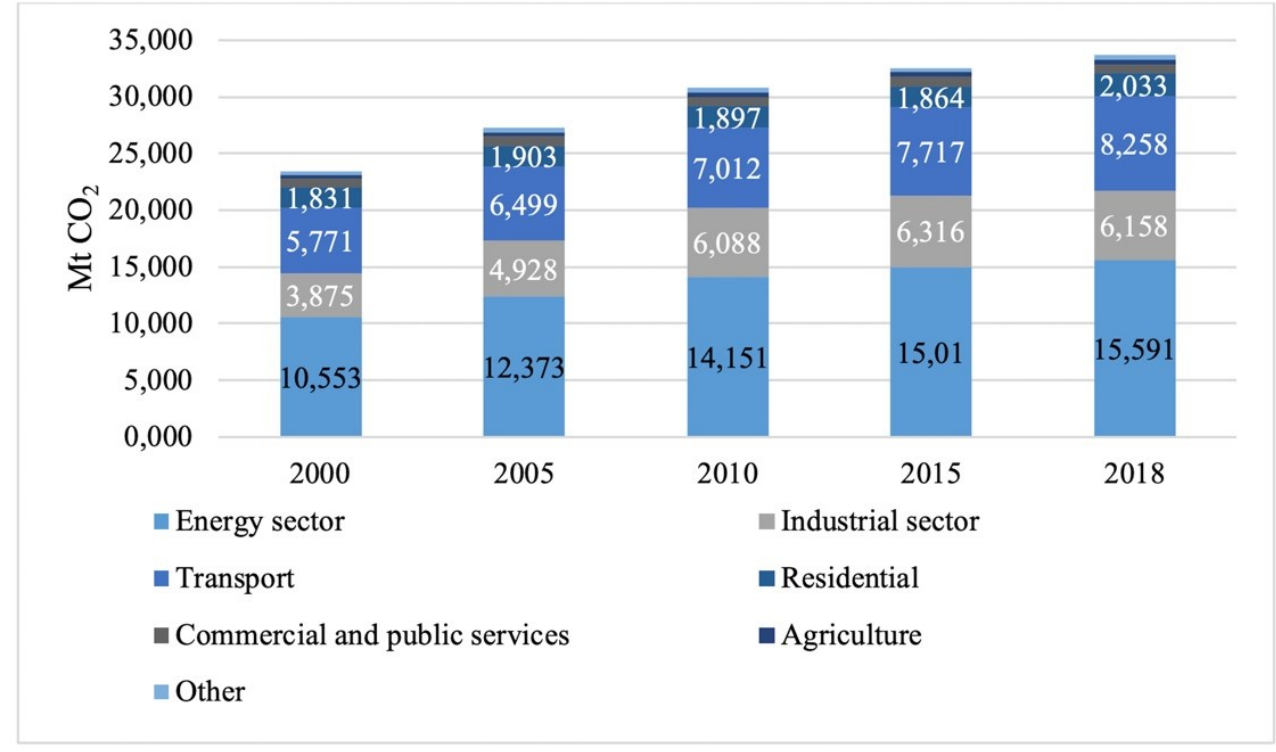

Fig. 1. $\mathrm{CO}_{2}$ emissions by sector in 2000-2018, $\mathrm{Mt} \mathrm{CO}_{2}$ (based on data from [4])

The energy industry shows an accelerated growth rate of $\mathrm{CO}_{2}$ emissions in comparison with global indicators: the global growth rate in the period $2000-2018$ was $42.5 \%$, while the growth rate of $\mathrm{CO}_{2}$ emissions produced by energy industry over the same period was $47.7 \%$. It corresponds to the growth of global energy consumption that is still dominated by the share of fossil fuels. Energy facilities that use fossil fuels as a main type of fuel for producing energy, emit $\mathrm{SO}_{2}$, NOx, $\mathrm{CO}$, heavy metal compounds, industrial particulate matter and other harmful substances into the atmosphere [5-8]. Moreover, they can generate large amount of ash and slag waste, pollute water bodies and the soil [9-12].

At the same time, the energy sector is a backbone branch of the economy. The livelihoods of population and the socio-economic development of many regions directly depend on the energy industry. Moreover, scientific and technological development and innovations in the energy sector stimulate economic growth [13-15]. Madlener and Alcott identified a direct relationship: increased energy efficiency leads to increased energy consumption, since increased energy efficiency reduces the cost of energy production, thereby stimulating economic growth first, and then energy consumption [16]. The availability of energy resources and meeting the growing demand for energy are the key factors of scientific and technological progress and economic growth [17, 18].

Since 2021, a new international climate-regulating legal regime has been operated within the framework of the Paris Agreement [19]. The key objective of the new regime is the steady reduction in greenhouse gas emissions into the atmosphere produced as a result of industrial and economic activities [19]. Moreover, the one of the 17 Sustainable Development Goals (SDGs) is "Affordable and clean energy", which also implies a gradual transition to renewable energy sources and an increase in their share in the structure of global energy production [20].

The measures and initiatives listed above encourage the governments of developed and developing countries to invest a greatest volume of financial resources in developing and eco-modernization of the energy sector [21-25]. Energy industry is a capital-intensive branch of the economy, with a fairly low degree of return and long payback periods for investment projects, but at the same time, energy is one of the most promising sectors of the 
economy, which annually attracts a significant amount of investment [26-28]. Figure 2 shows the dynamics of global investment in the energy sector of the economy.

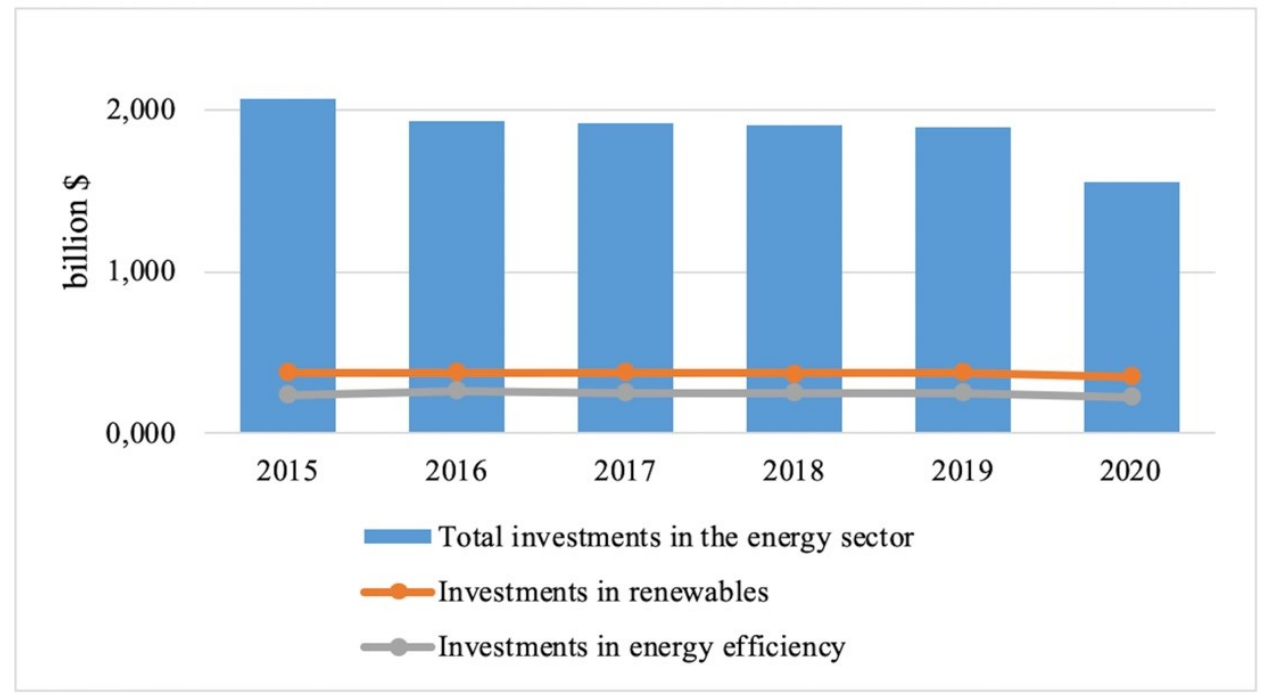

Fig. 2. World investments in the energy sector, billion \$ (based on data from [4])

Global investments in energy industry has shown a minor downward trend from 2015 to 2019. In 2020, there was a $25.1 \%$ decline in energy investment inflows, caused by the Covid-19 pandemic, which has slowed the growth of the largest economies in developed and developing countries [29-35]. However, the volume of investments in renewable energy and in improving energy efficiency remains almost unchanged throughout the analyzed period.

The crisis, caused by pandemic Covid-19, is expected to have a considerable impact on the energy investment activity. Aside from slowing growth of global economies, the Covid19 pandemic has identified new challenges for the energy sector: an increase in demand for electricity with a significant decline in energy demand and in energy prices, changes in global supply chains, the need for green energy development also from waste and raw biomasses, and increased risks of investing in projects related to fossil fuels [36-39]. The global transition to a new energy paradigm (reducing dependence on fossil fuels and switching to green energy) will require the implementation of large-scale investment projects for the eco-modernization of existing energy infrastructure and the development of new green energy sectors.

The governments of most states, as part of the recovery of their economies from the crisis, will continue to encourage the transition to a low-carbon economy, which should reduce the dependence of the socio-economic development of the territories on the cost of energy [36].

To reduce investment risks and improve both the ecological and economic efficiency of investment projects, it is necessary to enhance approaches to their environmental and economic assessment. The policy of decarbonization and the achievement of the SDGs has led to considerable changes in the environmental laws of many developed countries. Most states have tightened control over the implementation of energy projects. Now it is not only the economic indicators of the project that come to the forefront, but the environmental ones (e.g. reducing the human burden on the environment, possible long-term externalities caused by the project implementation) [22]. The most common approaches to the assessment of ecological and economic efficiency are "cost-benefit" approach and "cost- 
efficiency" approach that require adaptation to the specifics and current challenges of energy, which implies a revision of the current criteria for evaluating investment projects [40]. The purpose of this research is to determine the preliminary environmental criteria that should be included in the system of ecological and economic assessment of investment projects in the energy sector.

\section{Research methods}

To determine and rank the preliminary environmental criteria, the authors conducted a survey of Russian experts with the necessary competencies in the field of ecology, energy and investment. The survey was conducted using the online service "Google Forms".

The survey involves ranking of 17 criteria that can be used in the initial assessment of the ecological and economic efficiency of an investment project implemented at a traditional energy facility on a scale of one to ten. The choice of evaluation criteria was determined by the predominance of traditional energy facilities in the structure of electricity production in Russia (Figure 3).

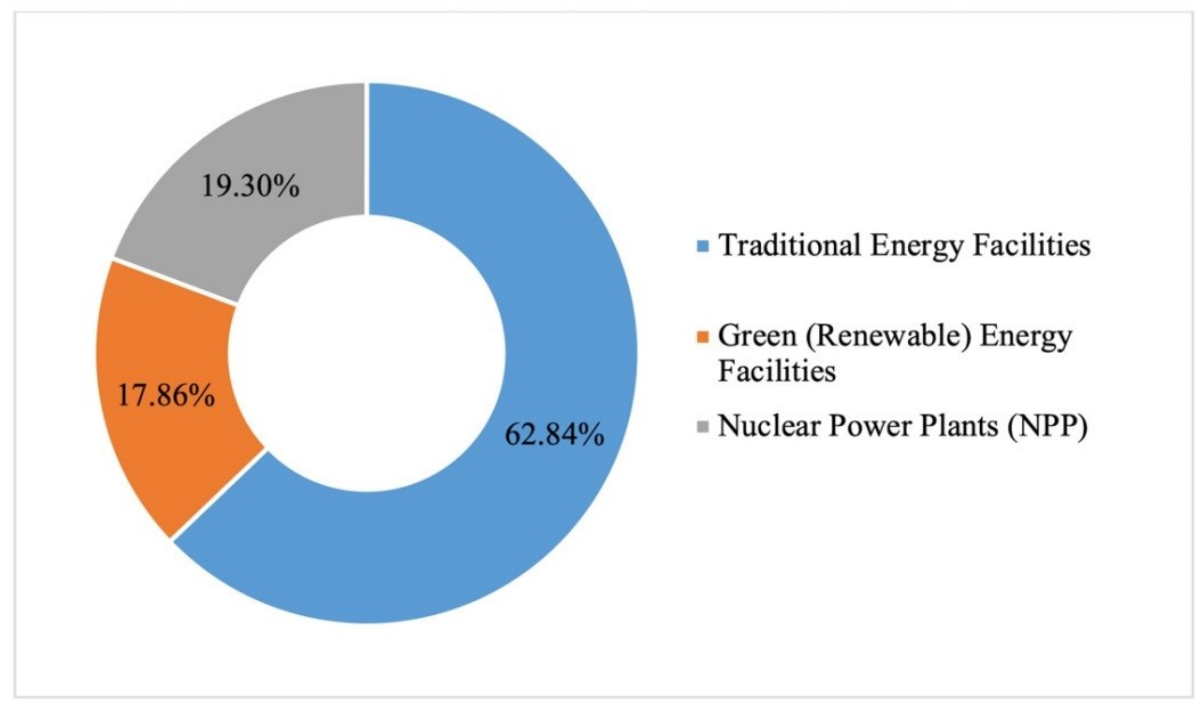

Fig. 3. Electricity production by the type of energy facility in Russia in $2019, \%$ (based on data from [41])

More than $60 \%$ of electricity in Russia is produced by thermal power plants (TPPs), $19.3 \%$ by NPPs. Renewable energy facilities, that include hydroelectric power plants, wind plants, and solar power plants, produce $17.86 \%$ of electricity, more than $98 \%$ of which is accounted for by hydroelectric power plants. It is assumed that most of the investment projects in the energy sector in Russia will be aimed to provide the eco-modernization of the existing energy infrastructure through the introduction of environmental technologies.

The survey consists of two parts. The first part considers ranking by the degree of importance of the enlarged criteria (mainly environmental) that should be included in the ecological and economic assessment of investment projects in the energy industry. The second part of the survey is the open question whose mission is identifying additional criteria for conducting an ecological and economic assessment. The first part of the survey was mandatory, the answers to the open question might have been entered at the request of the respondent. The survey form is shown in table 1 . 
Table 1. The structure of experts' questionnaire

\begin{tabular}{|c|c|}
\hline & The list of criteria / Answer \\
\hline \multirow{17}{*}{$\begin{array}{l}\text { 1. Here is a list of criteria that } \\
\text { can be used in the process of } \\
\text { assessment of environmental } \\
\text { and economic efficiency of } \\
\text { investment projects in the } \\
\text { energy industry, please rank the } \\
\text { criteria according to their } \\
\text { significance on a 10-point scale. }\end{array}$} & 1) Capacity of the energy facility. \\
\hline & $\begin{array}{l}\text { 2) Share of the energy facility in providing the locality with } \\
\text { electricity. }\end{array}$ \\
\hline & 3) Use of environmental technologies at energy facility. \\
\hline & $\begin{array}{l}\text { 4) Resource consumption by the energy facility for producing } \\
\text { energy }\end{array}$ \\
\hline & $\begin{array}{l}\text { 5) Coal consumption by the energy facility for producing } \\
\text { energy. }\end{array}$ \\
\hline & 6) Share of coal consumption in total resource consumption \\
\hline & $\begin{array}{l}\text { 7) Oil fuel consumption by the energy facility for producing } \\
\text { energy }\end{array}$ \\
\hline & 8) Share of oil fuel consumption in total resource consumption \\
\hline & $\begin{array}{l}\text { 9) Natural gas consumption by the energy facility for } \\
\text { producing energy }\end{array}$ \\
\hline & $\begin{array}{l}\text { 10) Share of natural gas consumption in total resource } \\
\text { consumption }\end{array}$ \\
\hline & 11) Total emissions of $\mathrm{CO} 2$ produced by the energy facility \\
\hline & 12) Total emissions of SO2 produced by the energy facility \\
\hline & 13) Total emissions of NOx produced by the energy facility \\
\hline & 14) The square occupied by energy facility \\
\hline & 15) Potential risks of the energy facility operation \\
\hline & 16) Social value of the energy facility \\
\hline & 17) Degree of the secondary use of industrial waste \\
\hline $\begin{array}{l}\text { 2. In your opinion, what } \\
\text { criteria, in addition to the } \\
\text { above, can be used to assess the } \\
\text { environmental and economic } \\
\text { efficiency of energy projects? }\end{array}$ & Open-ended question \\
\hline
\end{tabular}

\section{Results and discussion}

A total of 109 experts took part in the survey. Each expert evaluated the proposed criteria on a 10-point scale. In order to analyze the results obtained and rank the criteria, the following indicators were adopted:

- evaluation from 1 to 4 points - the criterion is insignificant in the framework of evaluating the ecological and economic efficiency of the investment project in the energy industry (it is not recommended to include it in the evaluation system);

- evaluation from 5 to 7 points - the criterion has an average degree of significance in the framework of assessing the ecological and economic efficiency of an investment project in the energy industry (it is recommended to include it in the evaluation system);

- evaluation from 8 to 10 points - the criterion plays a key role in the evaluation of the ecological and economic efficiency of the investment project in the energy industry (it should be included in the evaluation system).

Criteria "Capacity of energy facility" and "Share of the energy facility in providing the locality with electricity" allow to assess technical features of investment project: the more the capacity of the energy facility, the larger territory it can provide with electricity. Figure 4 shows the results of the respondents' assessment of both criteria. 


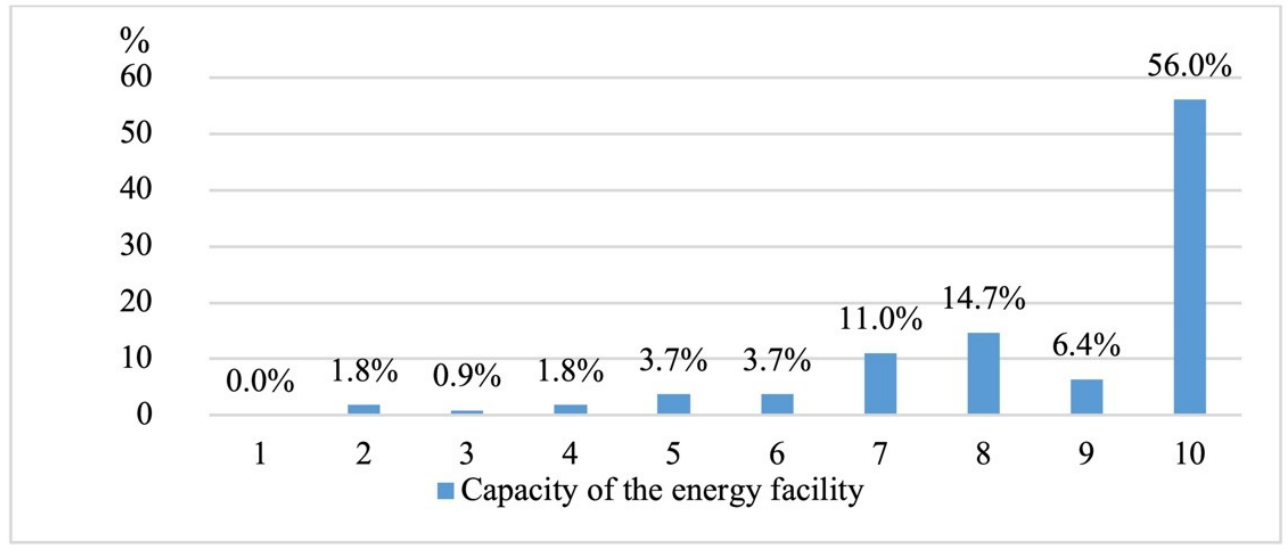

a)

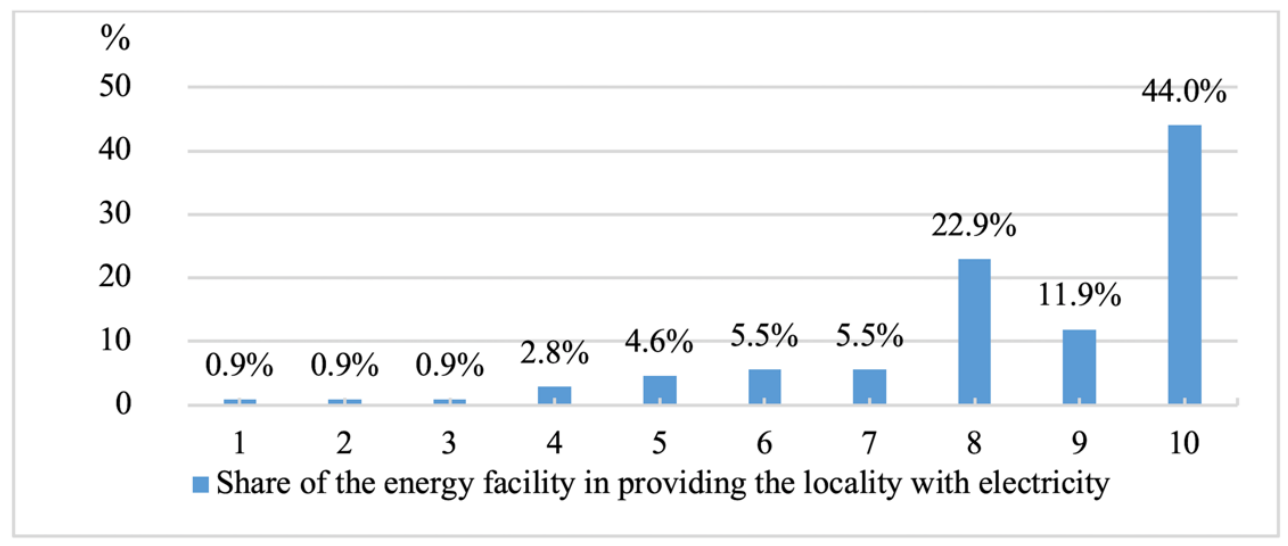

b)

Fig. 4. Results of assessment criteria "Capacity of energy facility" (a) "Share of the energy facility in providing the locality with electricity" (b) by respondents, \%.

More than $75 \%$ of respondents rated both criteria from 8 to 10 points. $56 \%$ of experts rated the capacity of energy facility at the maximum point. $44 \%$ gave a similar rating to the share of the energy facility in providing the locality with electricity. It indicates a need for including these criteria in the assessment process of environmental and economic efficiency of investment projects.

The third criterion "Use of environmental technologies at the energy facility" was rated by experts at a high level: $11 \%$ rated the criterion at 8 points, $7.3 \%$ at 9 points and $56 \%$ at 10 points. This criterion allows assessing the degree of innovation of the investment project considering environmental protection and its compliance with the current requirements of the environmental legislation of the country in which the project is being implemented [42].

Resource consumption at the energy facility is a key performance indicator in the energy sector. Traditional energy facilities consume considerable amount of minerals such as coal, oil and natural gas. It leads not only to the depletion of natural resources, but also to environmental pollution. In the process of mineral resource combustion, huge amount of $\mathrm{CO}_{2}$ emissions and other toxic substances are generated [43]. To reduce the negative impact of the energy facility on the environment, its consumption of natural resources must be reduced, and the process of energy production must be optimized too.

The majority of respondents consider the indicator of total resource consumption is an important component of the ecological and economic assessment of investment projects in 
the energy sector: $57.5 \%$ of respondents rated this criterion at a high level. In further, the experts had to assess the role of consumption of a particular type of fuel (coal, fuel oil, natural gas) and its specific weight in the structure of resource consumption in the framework of assessing the efficiency of the energy project.

According to the data obtained, more than $50 \%$ of experts consider it mandatory to include in the system of ecological and economic assessment the criteria for the consumption of all the listed types of fuel and to calculate their share in the total structure of resource consumption by the energy facility. The structure of resource consumption plays an important role in the implementation of eco-modernization projects: most traditional energy facilities are switching from coal-fired TPPs to gas-oil TPPs, which implies the use of more environmentally friendly natural gas as the main fuel [44]. Table 2 shows the ratio of expert assessments for each type of fuel.

Table 2. Criteria's assessment of resource consumption by energy facility

\begin{tabular}{|l|c|c|c|}
\hline \multirow{2}{*}{ Type of resource } & \multicolumn{3}{|c|}{ Experts' evaluation, \% } \\
\cline { 2 - 4 } & $1-4$ points & $5-7$ points & $8-10$ points \\
\hline Consumption & $16.7 \%$ & $21.2 \%$ & $62.1 \%$ \\
\hline Share in total resource consumption & $23.0 \%$ & $15.6 \%$ & $61.4 \%$ \\
\hline \multicolumn{3}{|c|}{ Fuel oil } \\
\hline Consumption & $16.8 \%$ & $30.0 \%$ & $53.2 \%$ \\
\hline Share in total resource consumption & $20.2 \%$ & $25.6 \%$ & $54.2 \%$ \\
\hline & Natural Gas \\
\hline Consumption & $4.0 \%$ & $24.6 \%$ & $71.8 \%$ \\
\hline Share in total resource consumption & $6.6 \%$ & $26.9 \%$ & $66.7 \%$ \\
\hline Total resource consumption & $5.4 \%$ & $17.7 \%$ & $76.9 \%$ \\
\hline
\end{tabular}

More than $60 \%$ of respondents noted the need to include all criteria of resource consumption in the system of environmental and economic assessment of investment projects in the energy sector.

Traditional energy facilities emit a huge amount of $\mathrm{CO}_{2}$ and other harmful substances such as $\mathrm{SO}_{2}$ and $\mathrm{NO}_{\mathrm{x}}$ into the atmosphere [45]. The experts were asked to assess the significance of the criteria for the release of these substances by the energy facility (fig. 5).

More than $70 \%$ of experts rated each of the proposed criteria "Total emissions of $\mathrm{CO}_{2}$ produced by the energy facility", "Total emissions of $\mathrm{SO}_{2}$ produced by the energy facility" and "Total emissions of $\mathrm{NO}_{\mathrm{x}}$ produced by the energy facility" from 8 to 10 points.

The lowest rank according to the results was given to the criterion "The square occupied by energy facility": $48.7 \%$ of respondents rated it from 5 to 7 points, that indicates its average level of significance in the framework of the ecological and economic assessment of the investment project.

According to the majority of respondents, the potential risks of operating an energy facility as an assessment criterion must be included in the project performance assessment system: $31.9 \%$ rated this criterion at $10 / 10$ points.

The criterion "Social value of the energy facility" was highly appreciated by the experts. It refers to the importance of an energy facility for maintaining the necessary level of socioeconomic development, providing the population and socially important infrastructure facilities (hospitals, kindergartens, schools) with electricity for carrying out current activities (fig. 6).

$68.1 \%$ of experts rated this criterion from 8 to 10 points, which indicates the need to include it in the process of ecological and economic assessment of investment projects. 


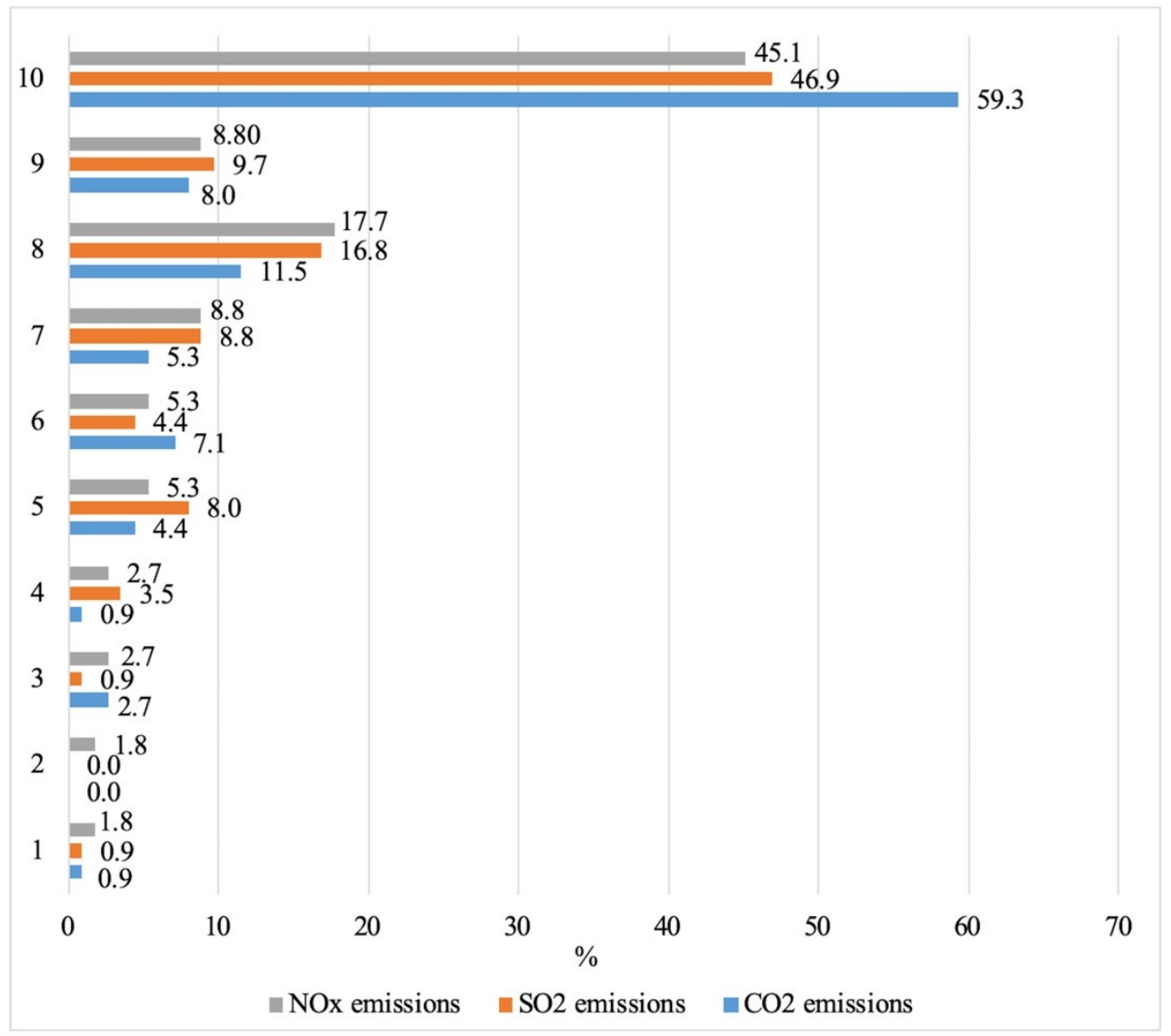

Fig. 5. Criteria's assessment of $\mathrm{CO}_{2}, \mathrm{SO}_{2}$ and $\mathrm{NO}_{x}$ emissions produced by energy facility, \%

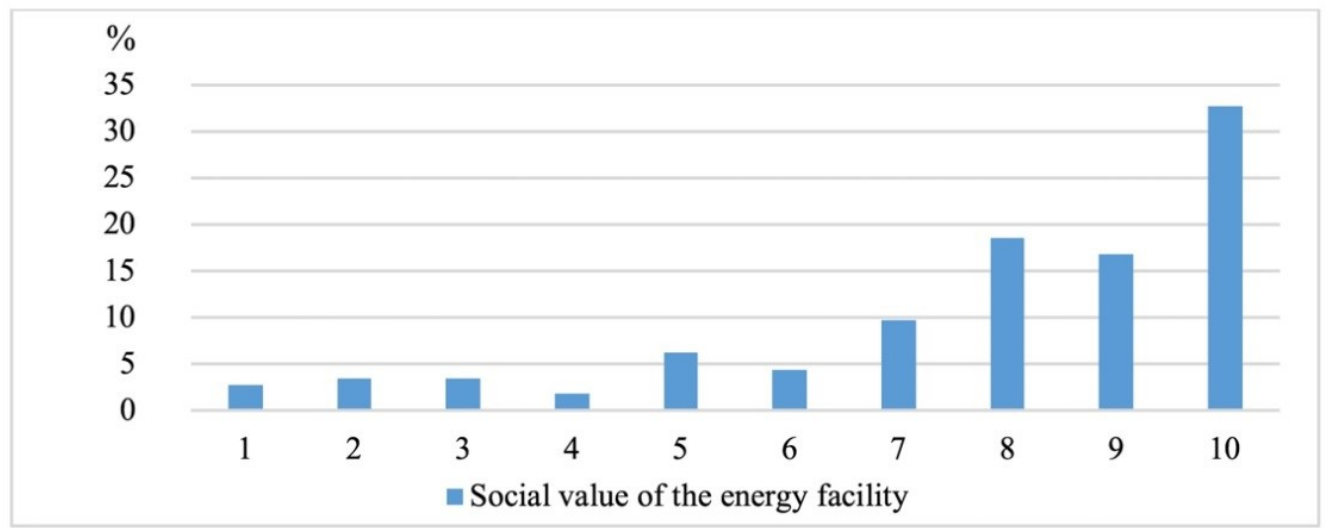

Fig. 6. Results of assessment criteria "Social value of the energy facility", $\%$

The final evaluation criterion was the secondary use of industrial waste at traditional energy facilities. Traditional energy companies, especially those that use coal as the main fuel, generate a significant amount of production waste that can be recycled. Figure 7 shows the results of the evaluation of this criterion by experts. 


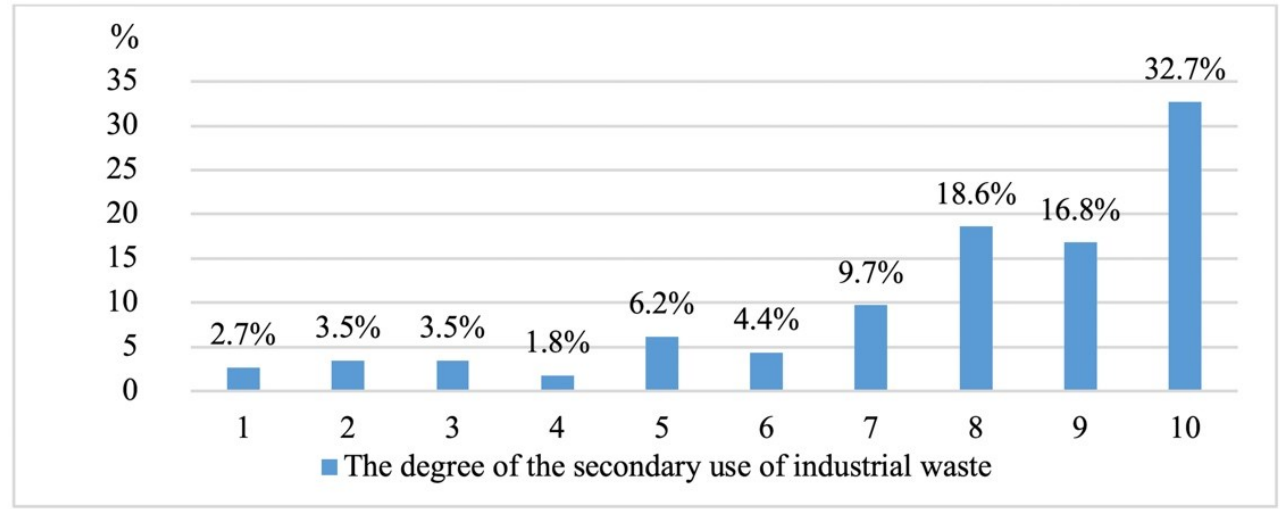

Fig. 7. Results of assessment criteria "The degree of the secondary use of industrial waste", $\%$

According to the results of the survey, the criterion of secondary use of industrial waste should be included in the process of environmental and economic assessment.

Thus, almost all the proposed criteria were evaluated by experts from 8 to 10 points. To identify the primary criteria, the authors ranked the results of the expert assessment by calculating the arithmetic mean for each criterion (Table 3).

Table 3. Calculation of average point of criteria assessment

\begin{tabular}{|l|c|}
\hline \multicolumn{1}{|c|}{ Criteria } & Average point \\
\hline Total emissions of $\mathrm{CO}_{2}$ produced by the energy facility & 8.71 \\
\hline Resource consumption by the energy facility for producing energy & 8.70 \\
\hline Capacity of energy facility & 8.66 \\
\hline Use of environmental technologies at energy facility & 8.51 \\
\hline Share of the energy facility in providing the locality with electricity & 8.42 \\
\hline Total emissions of $\mathrm{SO}_{2}$ produced by the energy facility & 8.37 \\
\hline Natural gas consumption by the energy facility for producing energy & 8.28 \\
\hline Total emissions of NOx produced by the energy facility & 8.17 \\
\hline Share of natural gas consumption in total resource consumption & 8.06 \\
\hline Social value of the energy facility & 7.95 \\
\hline Potential risks of the energy facility operation & 7.83 \\
\hline Degree of the secondary use of industrial waste & 7.81 \\
\hline Coal consumption by the energy facility for producing energy. & 7.31 \\
\hline Share of coal consumption in total resource consumption & 7.24 \\
\hline Share of oil fuel consumption in total resource consumption & 7.21 \\
\hline Oil fuel consumption by the energy facility for producing energy & 7.19 \\
\hline The area of energy facility & 6.19 \\
\hline
\end{tabular}

Based on the given results, authors made the following conclusions:

- 9 from 17 proposed criteria should be included in the assessment process of ecological and economic efficiency of investment projects in energy industry;

- the highest score among all the criteria was received by the indicator of $\mathrm{CO}_{2}$ emissions into the atmosphere -8.71 points, followed by the indicator of resource consumption (8.70) and the indicator of energy facility capacity (8.66). The resulting distribution of criteria is due to the fact that $\mathrm{CO}_{2}$ emissions into the atmosphere from the burning of fossil fuels correlate with emissions of gaseous toxic substances, being an indicator of the total human pressure on the environment, and the greater the density of the fuel used [4346];

- the importance of the criteria for the total consumption of natural gas by the energy facility and its share in the total structure of resource consumption ( 8.28 and 8.06 points, 
respectively) may be due to the policy of the Russian government in stimulating the transition of traditional energy facilities to the use of natural gas as the main fuel. Natural gas is eco-friendlier compared to coal and refined petroleum products and allows to reduce resource consumption with a constant amount of energy generation;

- the criterion for using the best available technologies scored 8.51 points, which indicates the need to take into account the technical component in the development and implementation of investment projects in the energy sector;

- the lowest rating was given to the criterion "The square occupied by energy facility" (6.19 points), which makes this criterion optional for inclusion in the project performance assessment system.

In the second part of the survey, experts were asked to name their criteria that might be used to assess the environmental and economic efficiency of energy projects. Only 16 out of 109 experts $(14.7 \%)$ provided additional criteria. The list of the proposed criteria by experts includes:

- water consumption by the energy facility ( 2 experts);

- share of innovations in the total amount of investments (2 experts);

- wastewater discharges by energy facility (1 expert);

- the green square occupied by the energy facility (1 expert);

- share of investments in the eco-modernization in the total amount of investments (1 expert);

- shares of governmental and private investments in the total amount of investments (1 expert).

Hence, all of the above criteria can be included in the evaluation system of an investment project in the energy sector. They cover both the environmental component (wastewater discharges by energy facility) and the economic component (share of innovations in the total amount of investments).

To increase the objectivity of the assessment of ecological and economic efficiency and to compare alternative investment projects, it is proposed to use relative environmental and economic indicators developed on the basis of mandatory and additional criteria determined as a result of the study. For instance, instead of the indicator "Total amount of $\mathrm{CO}_{2}$ emissions produced by the energy facility", it is proposed to use the indicator "Share of $\mathrm{CO}_{2}$ emissions from energy production, $\mathrm{t} / \mathrm{MWh}$ ". Similar indicators are proposed to be introduced for emissions of other toxic substances. Using relative indicators instead of absolute ones allows you to compare the efficiency of energy facilities, regardless of their size and rated capacity. The proposed approach increases the objectivity of the ecological and economic assessment and the informativeness of the results obtained.

\section{CONCLUSIONS}

Based on the results of the study, the authors formed a list of mandatory criteria that received an average expert rating of 8 to 10 points:

- total emissions of $\mathrm{CO}_{2}$ produced by the energy facility

- resource consumption by the energy facility for producing energy

- capacity of energy facility

- use of environmental technologies at energy facility

- share of the energy facility in providing the locality with electricity

- total emissions of $\mathrm{SO}_{2}$ produced by the energy facility

- natural gas consumption by the energy facility for producing energy 
- total emissions of $\mathrm{NO}_{\mathrm{x}}$ produced by the energy facility

- share of natural gas consumption in total resource consumption.

The selected environmental criteria cover only a part of the energy facility operation: air pollution, resource consumption, electricity generation. In this regard, the experts proposed the following additional evaluation criteria: water consumption by the energy facility, the volume of discharges of polluted wastewater by the energy facility, share of innovations in the total amount of investments, the area of the green territory used for the construction and operation of the energy facility, share of investments in the eco-modernization in the total amount of investments, and shares of state and non-state investments in the total amount of investments.

To develop a more comprehensive approach to assessing the ecological and economic efficiency of investment projects in the energy sector, it is necessary to include criteria for water consumption and water pollution by the energy facility, the criterion of innovation of the investment project, the investment structure, expand the criterion for assessing emissions of harmful substances into the atmosphere by introducing a common integral indicator of emissions, which will include not only emissions of $\mathrm{CO}_{2}, \mathrm{SO}_{2}$ and $\mathrm{NO}_{\mathrm{x}}$, but also emissions of PM, heavy metal compounds, benzo $(\alpha)$ pyrene and other toxic substances.

The list of criteria obtained as a result of the conducted research can be improved and used in the method of multicriteria decision analysis (MCDA). The method is based on a ranking of pre-defined criteria for an objective and transparent assessment of various solutions. Its use in the framework of ecological and economic assessment of investment projects will allow comparing alternative projects in the energy sector during their initial analysis, as a result of which the possible most preferred and inappropriate solutions will be determined.

This research is supported by Act 211 Government of the Russian Federation, contract No. 02.A03.21.0006.

\section{References}

1. T. Rokicki, A. Perkowska, B. Klepacki, H. Szczepaniuk, E.K. Szczepaniuk, S. Bereziński, P. Ziółkowska, Energies, 13(17), 4407 (2020)

2. L. Gitelman, E. Magaril, M. Kozhevnikov, E.C. Rada, Resources, 8(2), 73 (2019)

3. J.J. Klemeš, P.S. Varbanov, T.G. Walmsley, A. Foley, Renew Sust Energ Rev. 116, 109435, (2019)

4. International Energy Agency. World Energy Outlook 2020

5. E. Erdiwansyah, Mahidin, H. Husin, N. Nasaruddin, M. Zaki, Muhibbuddin, Pro Control Mo Power Syst, 6(1), 3 (2021)

6. Z. Li, T. Fang, C. Chen, Polish J Environ Stud, 30(2), 1695-1705 (2021)

7. J.J. Cartelle Barros, M. Lara Coira, M.P. de la Cruz López, A. del Caño Gochi, I. Soares, Appl Energy, 260, 114344 (2020)

8. S. Ciuta, M. Schiavon, A. Chistè, M. Ragazzi, E.C. Rada, M. Tubino, A. Badea, T. Apostol, UPB Sci Bull, Series D, 74(1), 211-218 (2012)

9. M.A.S. Eldean, A.M. Soliman, Appl. Energy 195 (2017)

10. A. Iatsyshyn, V. Artemchuk, A. Zaporozhets, O. Popov, V. Kovach, V., Std Syst Deci Control $298(2020)$

11. M. Tang, G. M. Mudd, Environ Sci Pollut Res Int 22(23), 18410-18424 (2015)

12. M.S., Mat-Shayuti, T.M.Y.S., Tuan Ya, M.Z., Abdullah, N.H. Alias, N.H., Othman, S. Zainal, Water, Air, Soil Pollut, 231(7), 369, (2020)

13. N. Apergis, J. Payne, Energy Econ, 31(2), 211-216 (2009)

14. C.C. Lee, C.P. Chang, Resour Energy Econ 30(1), 50-65 (2008) 
15. B.A. Gyamfi, F.F. Adedoyin, M.A. Bein, F.V. Bekun, D.Q. Agozie, J. Clean Prod. 295, $126373(2021)$

16. R. Madlener, B. Alcott, Energy 34(3), (2009)

17. D. Stern, Energy Econ 15(2), (1993)

18. E.F.E. Atta Mills, K. Zeng, M.A. Baafi, J Business Econ Manag, 21(1), (2020)

19. Paris Agreement on Climate Change. United Nations.

20. The 17 Goals. United Nations: Department of Economic and Social Affairs.

21. Z.Z. Li, R.Y.M. Li, M.Y. Malik, M. Murshed, Z. Khan, M. Umar, Sust Prod Consum, 27, (2021)

22. A. Karaeva, E. Magaril, E. C.Rada, WIT Transact Ecol Environ., 246, 113-123 (2020)

23. L.D., Gitelman, V.V., Dobrodey, M.V.Kozhevnikov, Econ Reg, 16(4), (2021)

24. V.G., Korolev, Ind Eng Manag Syst, 19(1), (2020)

25. V., Barro, BWK- Energie-Fachmagazin, 71(9), (2019)

26. M. Rajavuori, K. Huhta, Energy Policy, 144, 111646 (2020)

27. S. Norbu, B. Couraud, V. Robu, M. Andoni, D. Flynn, Appl. Energy, 287, 116575 (2021)

28. Communication from the Commission to the European Parliament, the Council, the European Economic and Social Committee and the Committee of the Regions. Energy roadmap 2050

29. I.Shaikh, Resour Policy, 72, 102025 (2021)

30. R. Selmi, J. Bouoiyour, S. Hammoudeh, Y. Errami, M.E. Wohar, Int Econ, 165, (2021)

31. M. Andrijevic, C.F. Schleussner, M.J. Gidden, D.L. McCollum, J. Rogelj, Sci, 370, 6514 (2020)

32. Available at: https://www.oxfordenergy.org/wpcms/wp-content/uploads/2020/07/COVID-19GLIMPSES-OF-THE-ENERGY-FUTURE.pdf

33. J.J. Klemes, Y.V. Fan, P.Jiang Keay, D. Robinson, Int J energy Res, 45(3), (2021)

34. S.E. Hosseini, Energy. Res. Social Sci, 68, 101633 (2020)

35. D. Cvetković, A. Nešović, I. Terzić, Energy Build, 230, 110532 (2021)

36. U. von der Leyen, Speech by President von der Leyen in the Plenary of the European Parliament at the debate on the European Green Deal. European Commission, Brussels, 2020.

37. L. Adami, M. Schiavon, E.C. Rada, Sci Total Environ, 740, 140078 (2020)

38. A. Kiselev, I. Glushankova, L. Rudakova, A. Baynkin, E. Magaril, E.C. Rada, Int J Energy Prod Manag, 5(3), (2020)

39. Z. Zhang, M. Lis, Sustainability, (4),1368, (2020)

40. M. Bianchi, I. Valle, C. Tapia, J. Clean Prod, 276, 123245 (2020)

41. Ministry of Energy of Russian Federation: Main characteristics of Russian electric power sector. (2021)

42. E. M. Ländner, A. Märtz, M. Schöpf, M. Weibelzahl, Energy Policy, 129, (2019)

43. E. Magaril, Environ Sci Pollut Res, 23(7), (2016)

44. R. Lazzarin, M. Noro, Appl. Therm. Eng., 26(2-3), (2006)

45. A. Elnakat, J.D. Gomez, N. Booth, Energy Rep, 2, (2016)

46. A. Golubeva, E. Magaril, WIT Transact Build Environ. 130, (2013) 